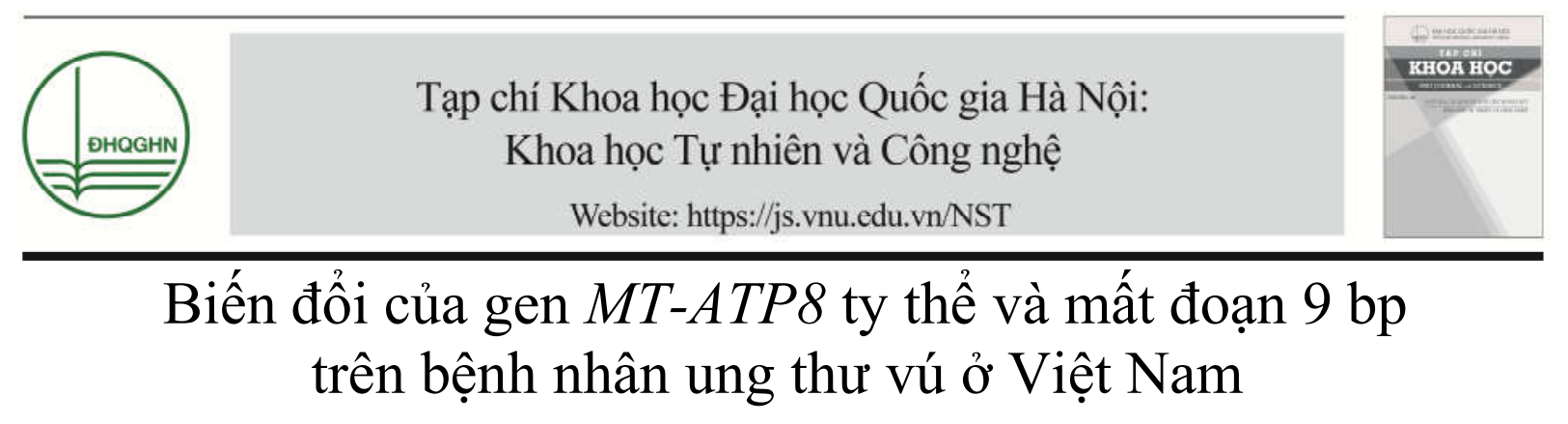

\author{
Nguyễn Thị Tú Linh, Nguyễn Thị Thảo, Đỗ Thị Dung, Trịnh Hồng Thái* \\ Truờng Đại học Khoa học Tụ nhiên, ĐHQG Hà Nội, 334 Nguyễn Trãi, Hà Nội, Việt Nam \\ Nhận ngày 16 tháng 8 năm 2017 \\ Chỉnh sửa ngày 20 tháng 9 năm 2017; Chấp nhận đăng ngày 10 tháng 10 năm 2017
}

\begin{abstract}
Tóm tắt: Gen $M T-A T P 8$ ty thể mã hóa cho tiểu đơn vị protein A6L thuộc kênh proton của phức hệ tổng hợp ATP. Biến đổi của gen $M T-A T P 8$ có thể ảnh hưởng tới cấu trúc và chức năng của enzyme ATP synthase, từ đó có thể gây bệnh. Trong nghiên cứu này, biến đổi của gen $M T-A T P 8$ được xác định trên mẫu mô của bệnh nhân ung thư vú và mẫu máu của người bình thường sử dụng phương pháp PCR kết hợp giải trình tự trực tiếp và PCR-RFLP, sau đó được phân tích và đánh giá bằng các phương pháp tin sinh học và thống kê sinh học. Kết quả $\mathrm{PCR}$ và giải trình tự trực tiếp đã xác định được 5 biến đổi của gen $M T-A T P 8$ trên 35 mẫu mô u của bệnh nhân ung thư vú và 26 mẫu máu của người bình thường, trong đó có 2 biến đổi làm thay đổi trình tự axít amin của phân tử protein tương ứng là $\mathrm{C} 8414 \mathrm{~T}$ và $\mathrm{C} 8417 \mathrm{~T}$. Biến đổi $\mathrm{C} 8417 \mathrm{~T}$ được sàng lọc tiếp bằng $\mathrm{PCR}-\mathrm{RFLP}$ và là biến đổi hiếm gặp với tần suất $0,98 \%$ (1/102 mẫu mô) của bệnh nhân ung thư vú. Biến đổi này làm thay đổi axít amin leucine thành phenylalanine $(\mathrm{L} 18 \mathrm{~F})$ thuộc vị trí bảo thủ của $\mathrm{A} 6 \mathrm{~L}$ và được dự đoán có nhiều khả năng làm thay đổi cấu trúc và chức năng của phân tử protein. Bên cạnh đó, mất đoạn 9 bp cũng được tìm thấy trong vùng không mã hóa của $\mathrm{ADN}$ ty thể có tần suất $26,5 \%$ (27/102 trường hợp) ở bệnh nhân và $27 \%$ (7/26 trường hợp) ở mẫu đối chứng. Như vậy, kết quả đã cho thấy đột biến C8417T ở vị trí bảo thủ của gen $M T-A T P 8$ thuộc loại hiếm gặp và lần đầu tiên được xác định thấy trong một nhóm bệnh nhân ung thư vú tại Việt Nam.
\end{abstract}

Từ khóa: ADN ty thể, MT-ATP8, Ung thư vú.

\section{Mở đầu}

Ty thể được coi là "nhà máy năng lượng" của tế bào vì nó tạo ra hơn $90 \%$ năng lượng ATP cho các hoạt động của tế bào. Để đảm nhận chức năng này, ty thể có hệ gen riêng với 37 gen mã hóa cho 13 protein của các phức hệ

\footnotetext{
*Tác giả liên hệ. ĐT.: 84-243-8582798.

Email: thaith@vnu.edu.vn

https://doi.org/10.25073/2588-1140/vnunst.4713
}

hô hấp ty thể (phức hệ I - V), 2 ARN ribosome và $22 \mathrm{ARN}$ vận chuyển [1]. Ty thể cũng giữ vai trò quan trọng trong chết theo chương trình (apoptosis) của tế bào, do đó biến đổi của các gen ty thế được cho là có liên quan với quá trình tạo $\mathrm{u}$ bởi vì các tế bào ung thư cần sử dụng nhiều năng lượng để sinh trưởng và tăng sinh dưới các điều kiện hạn chế [2].

Trong các phức hệ hô hấp ty thể, phức hệ $\mathrm{V}$ là phức hệ tổng hợp ATP. Nó bao gồm một 
kênh proton nằm ở trên màng của ty thể $\left(\mathrm{F}_{0}\right)$ và một thành phần xúc tác $\left(\mathrm{F}_{1}\right)$ nằm ở trong chất nền. Trong số 9 tiểu đơn vị của $\mathrm{F}_{0}, 2$ tiểu đơn vị $\alpha$ và $\mathrm{A} 6 \mathrm{~L}$ được mã hóa bởi các gen $M T-A T P 6$ và $M T-A T P 8$ của ty thể [3]. Đột biến trong trình tự mã hóa cho 2 tiểu đơn vị này của phức hệ tổng hợp ATP có thể ảnh hưởng tới cấu trúc và chức năng của enzyme ATP synthase [4].

Gen MT-ATP8 (còn được gọi với tên khác là ATP8 hay ATPase 8) có kích thước $207 \mathrm{bp}$, nằm từ vị trí 8366 đến 8572 trên sợi nặng của $\mathrm{ADN}$ ty thể và mã hóa cho tiểu đơn vị $\mathrm{A} 6 \mathrm{~L}$. Gen này mã hóa cho phân tử protein thuộc vùng có chức năng quan trọng của phức hệ tổng hợp ATP, tuy nhiên vai trò các biến đổi của gen MT-ATP8 trong ung thư vẫn chưa được quan tâm nghiên cứu đầy đủ. Do đó, nghiên cứu này được thực hiện nhằm đánh giá biến đổi của gen $M T-A T P 8$ ty thể và tìm hiểu mối liên quan giữa các biến đổi này với các đặc điểm bệnh học của ung thư vútrên một nhóm đối tượng bệnh nhân người Việt Nam.

\section{Nguyên liệu và phương pháp}

\subsection{Nguyên liệu}

Mẫu nghiên cứu bao gồm mẫu mô ung thư biểu mô ống tuyến vú (được lấy tại vị trí khối u, gọi là mô u) của 102 bệnh nhân ung thư vú được phẫu thuật triệt căn có vét hạch và chẩn đoán xác định bằng mô bệnh học tại Khoa Giải phẫu bệnh - Tế bào, Bệnh viện $\mathrm{K}$ trong thời gian từ tháng $12 / 2012$ đến tháng $12 / 2013$ và mẫu máu của 26 người cho máu bình thường do Khoa Sàng lọc máu, Viện Huyết học và Truyền máu Trung ương cung cấp. Các mẫu bệnh phẩm được lấy vào vùng không bị hoại tử và loại trừ các trường hợp ung thư di căn từ nơi khác đến. Danh sách một số đặc điểm bệnh học bao gồm độ tuổi, kích thước khối u, số hạch, kích thước hạch, giai đoạn TNM (u nguyên phát - hạch tại vùng - di căn $\mathrm{xa}$ ) và mức độ biệt hóa của khối u được cung cấp kèm theo mẫu bệnh phẩm. Nghiên cứu được thực hiện đúng theo các quy định hiện hành về đạo đức trong nghiên cứu $\mathrm{y}$ học trong việc thu thập các mẫu máu và mô của bệnh nhân. Các dẫn liệu thu được đều được giữ bí mật, chỉ phục vụ cho mục đích nghiên cứu, không sử dụng cho mục đích nào khác.

\subsection{Phuong pháp}

Tách chiết ADN tổng số và PCR giải trình tụ trưc tiếp: $\mathrm{ADN}$ tổng số được tách chiết từ mẫu mô và mẫu máu sử dụng QIAamp DNA Mini Kit và QIAamp DNA Blood Mini Kit (QIAGEN, Đức) theo quy trình của nhà sản xuất. Nồng độ $\mathrm{ADN}$ tồng số được xác định bằng máy quang phổ NanoDrop 2000c (Thermoscientific, Mỹ). Các cặp mồi đặc hiệu cho từng đoạn $\mathrm{ADN}$ quan tâm được thiết kế sử dụng chương trình Primer-BLAST với trình tự $\mathrm{ADN}$ ty thể được tham khảo từ cơ sở dữ liệu trong NCBI (mã số NC_012920.1) (Bảng i). Thành phần của phản ứng $\mathrm{PCR}$ nhân bản đoạn $\mathrm{ADN}$ có kích thước $1148 \mathrm{bp}$ sử dụng để giải trình tự bao gồm: 6,25 $\mu 1$ Maxima Hot Start PCR Master Mix 2X; $0,25 \mu 1$ mỗi mồi $(0,2$ $\mu \mathrm{M}$ ); khuôn ADN (với nồng độ từ $1-2,5 \mathrm{ng} / \mu \mathrm{l}$ ) và $\mathrm{H}_{2} \mathrm{O}$ trong tổng thể tích $12,5 \mu \mathrm{l}$. Hỗn hợp phản ứng được chạy trên máy GenAmp ${ }^{\circledR} \mathrm{PCR}$ System 9700 với chu trình nhiệt như sau: $95^{\circ} \mathrm{C}$ : 4 phút, 35 chu kỳ $\left(95^{\circ} \mathrm{C}: 30\right.$ giây; $56^{\circ} \mathrm{C}: 30$ giây; $72^{\circ} \mathrm{C}: 75$ giây); $72^{\circ} \mathrm{C}$ : 5 phút, sau đó giữ ở $4^{\circ} \mathrm{C}$. Sản phẩm PCR được điện di kiểm tra trên gel agarose $1,5 \%$, tinh sạch bằng ExoSAP-IT (Affymetrix, Mỹ) và giải trình tự (Công ty $1^{\text {st }}$ Base, Malaysia).

Dự đoán khả năng gây bệnh của biến đổi dựa trên sư thay đổi trình tư axít amin: Tác động của các biến đổi gen làm thay đổi trình tự axít amin đến cấu trúc và chức năng của phân tử protein được dự đoán bằng chương trình PolyPhen-2[5].

Sàng lọc biến đổi C8417T sủ dụng phương pháp PCR-RFLP: Đoạn gen MT-ATP8 mang biến đổi C8417T (được dự đoán có vai trò quan trọng đến phân tử protein) được tiến hành nhân bản sử dụng cặp mồi 8417 (Bảng 1) với thành phần phản ứng bao gồm: $6,25 \mu 1$ Maxima Hot Start PCR Master Mix 2X; $0,25 \mu 1$ mỗi mồi $(0,2$ $\mu \mathrm{M}$ ); khuôn $\mathrm{ADN}$ (với nồng độ từ $1-2,5 \mathrm{ng} / \mu \mathrm{l}$ ) và $\mathrm{H}_{2} \mathrm{O}$ trong tổng thể tích $12,5 \mu 1$. Chu trình 
nhiệt sử dụng với cặp mồi 8417 được thiết lập như sau: $95^{\circ} \mathrm{C}$ : 4 phút, 35 chu kỳ $\left(95^{\circ} \mathrm{C}\right.$ : 30 giây; $52^{\circ} \mathrm{C}: 30$ giây; $72^{\circ} \mathrm{C}: 30$ giây); $72^{\circ} \mathrm{C}: 5$ phút, sau đó giữ ở $4^{\circ} \mathrm{C}$. Sản phẩm PCR có kích thước 255 bp được xử lý với enzyme giới hạn
DdeI (Thermo Scientific, Mỹ) theo hướng dẫn của nhà sản xuất. Sản phẩm cắt enzyme giới hạn được điện di kiểm tra trên gel polyacrylamide $8 \%$.

Bảng 1. Trình tự các cặp mồi và enzyme giới hạn sử dụng trong xác định biến đổi của gen $M T-A T P 8$

\begin{tabular}{|c|c|c|c|c|c|c|c|}
\hline \multirow[b]{2}{*}{ Mục đích } & \multirow{2}{*}{$\begin{array}{l}\text { Tên } \\
\text { mồi }\end{array}$} & \multirow{2}{*}{$\begin{array}{l}\text { Kích thước } \\
\text { sản phẩm } \\
\text { (vị trí) }\end{array}$} & \multirow{2}{*}{$\begin{array}{l}\text { Trình tự } \\
\text { mồi xuôi } \\
\left(5^{\prime}-3^{\prime}\right)\end{array}$} & \multirow{2}{*}{$\begin{array}{l}\text { Trình tự mồi } \\
\text { ngược }\left(5^{\prime}-3^{\prime}\right)\end{array}$} & \multirow{2}{*}{$\begin{array}{l}\text { Enzyme sử } \\
\text { dụng }\end{array}$} & \multicolumn{2}{|c|}{ Sản phẩm cắt } \\
\hline & & & & & & $\begin{array}{l}\text { Không } \\
\text { biến đổi }\end{array}$ & $\begin{array}{l}\text { Có biến } \\
\text { đổi }\end{array}$ \\
\hline $\begin{array}{l}\text { Giải trình } \\
\text { tự }\end{array}$ & ATP8 & $\begin{array}{l}1148 \mathrm{bp} \\
(8197-9344)\end{array}$ & $\begin{array}{l}\text { cagtttcatg } \\
\text { cccatcgt }\end{array}$ & $\begin{array}{l}\text { gcctagtatgaggag } \\
\text { cgtta }\end{array}$ & - & - & - \\
\hline $\begin{array}{l}\text { Sàng lọc } \\
\text { biến đồi } \\
\text { C } 8417 T\end{array}$ & 8417 & $\begin{array}{l}255 \mathrm{bp} \\
(8185-8439)\end{array}$ & $\begin{array}{l}\text { tggagcaaa } \\
\text { ccacagtta } \\
\text { c }\end{array}$ & $\begin{array}{l}\text { tgggtgatgaggaat } \\
\text { agtctaa }\end{array}$ & $\begin{array}{l}\text { DdeI } \\
\text { 5'C } \downarrow \text { TNAG 3, }\end{array}$ & $\begin{array}{l}125 \mathrm{bp} \\
108 \mathrm{bp} \\
22 \mathrm{bp}\end{array}$ & $\begin{array}{l}125 \mathrm{bp} \\
130 \mathrm{bp}\end{array}$ \\
\hline
\end{tabular}

Các phần mềm tin sinh học và phân tỉch thống kê: Các mồi đặc hiệu cho phản ứng PCR được thiết kế bằng chương trình Primer BLAST (NCBI). Trình tự các gen ty thể được so sánh, phân tích với trình tự tham chiếu của $\mathrm{ADN}$ ty thể công bố trên cơ sở dữ liệu NCBI (NC 012920.1) bằng các phần mềm tin sinh học chuyên dụng như BioEdit v7.0, BLAST và ClustalX. Xác định sản phẩm cắt enzyme giới hạn bằng chương trình Watcut. So sánh thống kê được thực hiện bằng kiểm định $\chi^{2}$ hoặc kiểm định Fisher (Fisher's exact test) để phân tích mối liên quan giữa các biến đổi với các đặc điểm bệnh học của ung thư vú.

\section{Kết quả}

3.1. Giải trình tư gen MT-ATP8 ty thể và phân tích các dạng biến đổi

Trong nghiên cứu này, đoạn $\mathrm{ADN}$ chứa gen $M T-A T P 8$ có kích thước 1148 bp được nhân bản và sử dụng để giải trình tự trực tiếp nhằm xác định các dạng biến đổi. Kết quả giải trình tự trực tiếp trên 35 mẫu mô u của bệnh nhân ung thư vú và 26 mẫu máu đối chứng đã phát hiện thấy 5 biến đổi của gen $M T-A T P 8$ là $\mathrm{C} 8410 \mathrm{~T}, \mathrm{C} 8414 \mathrm{~T}, \mathrm{C} 8417 \mathrm{~T}, \mathrm{~A} 8440 \mathrm{G}$ và T8473C (Hinh 1).
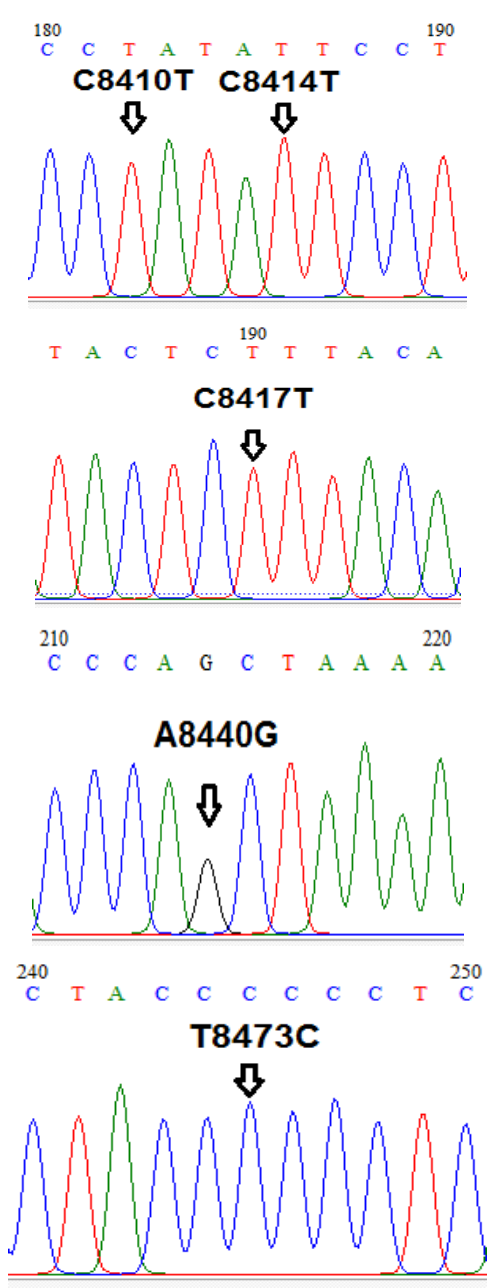

Hình 1. Các biến đổi của gen $M T$-ATP8 xác định thông qua giải trình tự trực tiếp 
Trong các biến đổi trên có 3 biến đổi C8414T, $A 8440 G$ và T8473C được thấy xuất hiện đồng thời ở mẫu mô của bệnh nhân và mẫu máu đối chứng. Các biến đổi của gen $M T-A T P 8$ ở mẫu mô và máu có tần suất thấp, xuất hiện ở $2 / 35$ bệnh nhân (chiếm $5,7 \%$ ) và $2 / 26$ đối chứng (chiếm 7,7\%) (Bảng 2). Tất cả các biến đổi đều ở trạng thái đồng tế bào chất (homoplasmy) và đã được báo cáo trên cơ sở dữ liệu của Mitomap. Đáng chú ý, có $2 / 5$ biến đổi (chiếm 40\%), C8414T và C8417T, là làm thay đổi trình tự axít amin của phân tử protein (Bảng 2).

Bảng 2 . Thống kê biến đổi của gen $M T-A T P 8$ trên mẫu mô u của bệnh nhân ung thư vú và mẫu máu bình thường xác định bằng giải trình tự trực tiếp

\begin{tabular}{lllllll}
\hline TT & Vị trí & Biến đổi & Thay đổi axít amin & $\begin{array}{l}\text { Tần suất } \\
\text { Mẫu mô }\end{array}$ & Mẫu máu & Công bố \\
\hline 1 & 8410 & C $>$ T & P15P & $1 / 35$ & - & + \\
2 & 8414 & C $>$ T & L17F & $1 / 35$ & $1 / 26$ & Longevity \\
3 & 8417 & C $>$ T & L18F & $1 / 35$ & - & + \\
4 & 8440 & A $>$ G & Q25Q & - & $1 / 26$ & + \\
5 & 8473 & T $>$ C & P36P & $1 / 35$ & $1 / 26$ & + \\
\hline
\end{tabular}

Chú thích: (+): Đã công bố trên MITOMAP

\subsection{Tác động của biến đổi gen làm thay đổi trình tụ axit amin}

Mặc dù biến đổi C8414T đã được báo cáo trước đây trong bệnh ung thư vú [6], tuy nhiên trong nghiên cứu này, biến đổi C8414T được phát hiện thấy trong cả mẫu mô của bệnh nhân và mẫu máu của người bình thường. Do đó, chúng tôi lựa chọn phân tích biến đồi C8417T, là biến đổi làm thay đổi trình tự axít amin của phân tử protein, thấy xuất hiện trên mẫu mô của bệnh nhân và không thấy trong mẫu máu đối chứng để tiến hành các phân tích tiếp theo.

Vai trò của biến đổi C8417T (L18F) đến cấu trúc và chức năng của phân tử protein $\mathrm{A} 6 \mathrm{~L}$ được dự đoán sử dụng chương trình PolyPhen2. Theo đó, biến đổi này nằm ở vị trí bảo thủ và được dự đoán là có nhiều khả năng ảnh hưởng đến phân tử protein (PolyPhen-2 score: 0,994). Tiếp theo, chúng tôi thực hiện sàng lọc biến đồi này trong các mẫu nghiên cứu.

\subsection{Tần suất biến đổi C8417T trong các mẫu nghiên cứu}

Để phân tích biến đổi C8417T trong các mẫu nghiên cứu, đoạn $\mathrm{ADN}$ có kích thước 255 bp có chứa vị trí biến đổi 8417 được nhân bản (Giếng 1, 3, 5, Hình 2) và sàng lọc trên các mẫu nghiên cứu sử dụng enzyme DdeI (Thermo Scientific, Mỹ) có vị trí nhận biết $\mathrm{C}^{\wedge} \mathrm{TNAG}$.

Theo tính toán, nếu không có biến đổi (8417C) thì enzyme giới hạn sẽ cắt sản phẩm PCR có kích thước 255 bp thành 3 đoạn $\mathrm{ADN}$ tương ứng là $125 \mathrm{bp}, 108 \mathrm{bp}$ và $22 \mathrm{bp}$. Trên gel polyacrylamide $8 \%$, dạng này được xác định nhờ vào 2 băng 125 bp và 108 bp (Giếng 4, Hình 2). Ngược lại, nếu có biến đổi (8417T) thì enzyme giới hạn sẽ cắt sản phẩm PCR có kích thước $255 \mathrm{bp}$ thành 2 đoạn $\mathrm{ADN}$ tương ứng là $130 \mathrm{bp}$ và $125 \mathrm{bp}$. Trên gel polyacrylamide $8 \%$, dạng $8417 \mathrm{~T}$ được xác định nhờ vào 1 băng có kích thước $\sim 130 \mathrm{bp}$.

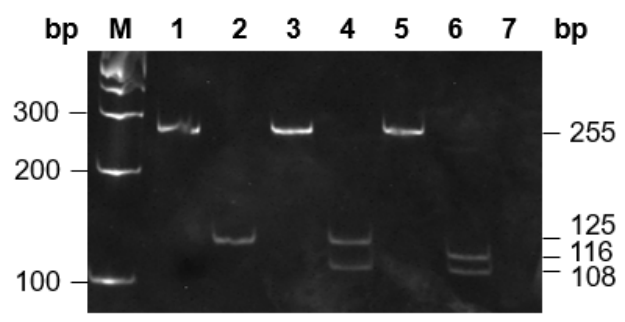

Hình 2. Ảnh điện di sản phẩm PCR với cặp mồi 8417 và sản phẩm cắt xác định biến đổi C $8417 \mathrm{~T}$ bằng enzyme $D d e$ I trên gel polyacrylamide $8 \%$

M: Thang chuẩn $\mathrm{ADN} 100$ bp. Giếng 1, 3, 5: sản phẩm PCR mẫu mô u của bệnh nhân (\#30698, \#33114, \#33157). Giếng 2, 4, 6: Sản phẩm cắt bằng enzyme DdeI mẫu mô u của bệnh nhân (\#30698, \#33114,\#33157). Giếng 7: Đối chứng âm $\left(\mathrm{H}_{2} \mathrm{O}\right)$. 
Kết quả sàng lọc trên 102 mẫu mô của bệnh nhân ung thư vú cho thấy có $1 / 102$ mẫu (chiếm $0,98 \%$ ) có biến đổi C8417T và 101/102 mẫu bệnh không có biến đổi tại vị trí 8417 (chiếm $99,02 \%$ ). Kết quả sàng lọc trên 26 mẫu máu đối chứng cho thấy tất cả các mẫu máu đối chứng đều không có biến đổi C8417T.

\subsection{Mất đoạn 9 bp thuộc vùng không mã hóa của ADN ty thể trong các mẫu nghiên cưu}

Kết quả điện di sản phẩm cắt bằng enzyme $D d e I$ cho thấy ngoài các băng $\mathrm{ADN}$ có kích thước $\sim 125$ bp và 108 bp theo đúng tính toán ban đầu, một số mẫu có xuất hiện thêm băng $\mathrm{ADN}$ có kích thước lạ khác. Các mẫu này được tinh sạch và tiến hành giải trình tự trực tiếp nhằm xác định biến đổi. Kết quả giải trình tự cho thấy ở các mẫu này có xuất hiện 1 mất đoạn nhỏ có kích thước $9 \mathrm{bp}$, có trình tự CCCCCTCTA, nằm ở vị trí $8272-8280$ trong vùng không mã hóa của $\mathrm{ADN}$ ty thể (giữa gen $M T-C O 2$ và $M T-T K)$ (Hình 3). Mất đoạn $9 \mathrm{bp}$ làm cho sản phẩm cắt có kích thước $125 \mathrm{bp}$ trở thành sản phẩm chỉ có kích thước 116 bp (Giếng 6, Hình 2).
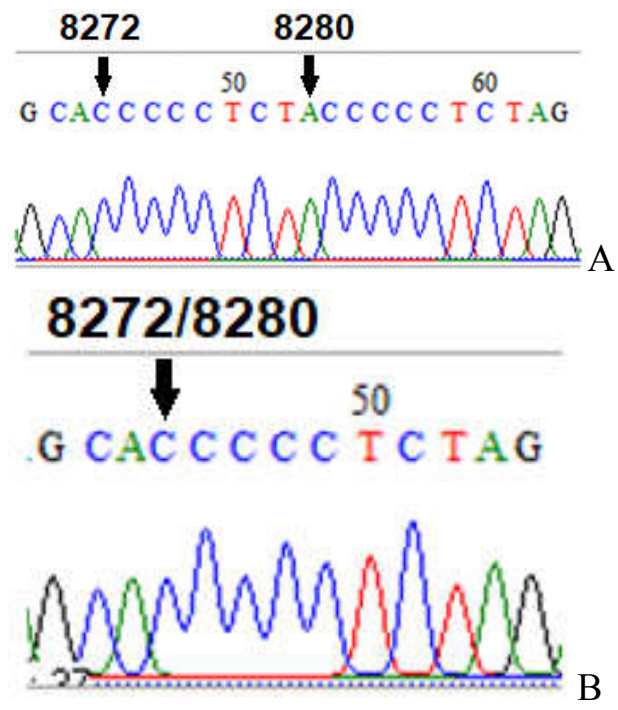

Hình 3. Kết quả giải trình tự xác định mất đoạn 9 bp $(8272-8280)$

A: Không có mất đoạn 9 bp. B: Có mất đoạn 9 bp.
Kết quả sàng lọc trên các mẫu nghiên cứu phát hiện thấy 27/102 trường hợp có mất đoạn 9 bp ở mô u của bệnh nhân ung thư vú (chiếm $26,5 \%$ ) và $7 / 26$ trường hợp có mất đoạn 9 bp (chiếm $27 \%$ ) ở máu đối chứng. Phân tích tần suất xuất hiện của mất đoạn 9 bp này theo các đặc điểm bệnh học của ung thư vú cho thấy không có sự khác biệt có ý nghĩa thống kê theo mức độ biệt hóa (rõ, vừa và kém) của khối $\mathrm{u}$, kích thước hạch $\left(\mathrm{N}_{0}\right.$ so với $\left.\mathrm{N}_{1-2}\right)$, số hạch $(<10$ hạch và $\geq 10$ hạch) và giai đoạn $T\left(T_{1-2}\right.$ và $\left.T_{3-4}\right)$ $(\mathrm{p}>0,05)$. Tuy nhiên, mất đoạn này lại thấy cao hơn có ý nghĩa thống kê ở độ tuổi $\geq 50(21 / 62$ trường hợp, chiếm $33,9 \%$ ) so với độ tuổi $<50$ (6/32 trường hợp, chiếm 18,8\%) (dữ liệu không được báo cáo).

\section{Bàn luận}

Vai trò của $\mathrm{ADN}$ ty thể liên quan với quá trình phát sinh ung thư đã được báo cáo rất sớm từ những năm 1920 khi Otto Warburg phát hiện thấy các tế bào ung thư cần sử dụng nhiều năng lượng ATP cho tăng sinh nhanh chóng thông qua tổng hợp bằng con đường đường phân (glycosis) nhiều hơn, thay vì sử dụng phosphoryl hóa oxy hóa (OXPHOS) ở ty thể [7]. Điều này cho thấy chức năng của OXPHOS và $\mathrm{ADN}$ ty thể có thể bị biến đổi trong các tế bào ung thư [8].

Gen MT-ATP8 mã hóa cho tiểu đơn vị A6L của phức hệ ATP synthase, enzyme chịu trách nhiệm chính trong tổng hợp ATP của tế bào, do đó các biến đổi của gen $M T-A T P 8$ có thể ảnh hưởng đến chức năng tổng hợp ATP và có thể gây bệnh [9]. Ví dụ như đột biến G8529A nằm ở vùng gối lên nhau giữa 2 gen $M T-A T P 6$ và $M T-A T P 8$ trên $\mathrm{ADN}$ ty thể đã được báo cáo trước đây. Mặc dù đột biến này không làm thay đổi trình tự axít amin của phân tử protein $\alpha$ do gen MT-ATP6 mã hóa nhưng lại tạo ra một bộ ba kết thúc sớm trong vùng bảo thủ của gen MT-ATP8 (W55X). Do đó, biến đổi này dẫn đến việc lắp ráp không chính xác và làm giảm hoạt tính của holoenzyme phức hệ V [10]. Một đột biến khác, T8528C, cũng được cho là đột 
biến gây bệnh vì nó dẫn đến sự thay thế axít amin tryptophan (có tính kỵ nước, bảo thủ cao) thành arginine (có tính kiềm cao) thuộc tiểu đơn vị $\mathrm{A} 6 \mathrm{~L}$ do gen $M T-A T P 8$ mã hóa và thay đổi mã bộ ba mở đầu dịch mã trong gen MT-ATP6 làm thay thế methionine thành threonine trong tiểu đơn vị $\alpha$ của phức hệ $\mathrm{V}$. Do đó, biến đổi này có thể ảnh hưởng đến cả 2 tiểu đơn vị của phức hệ $\mathrm{V}$ ty thể [11].

Biến đổi của gen $M T-A T P 8$ đã được báo cáo trong một số loại ung thư như C8414T (L17F), A8459G (N32D) và C8472T (P36L) trong ung thư buồng trứng [12], [13], C8468T và $\mathrm{C} 8472 \mathrm{~T}(\mathrm{P} 36 \mathrm{~L})$ trong ung thư tuyến giáp [1],[15], C8395T và $\mathrm{C} 8515 \mathrm{~T}$ trong ung thư tuyến cận giáp [16] (Bảng 3)... Trong các nghiên cứu này, đa số các biến đồi của gen $M T$ $A T P 8$ xuất hiện với tần suất thấp và không làm thay đổi trình tự axít amin của phân tử protein. Trên đối tượng bệnh nhân ung thư vú, dữ liệu ban đầu về biến đổi của gen $M T-A T P 8$ thu được rất khác biệt trên các nhóm bệnh nhân khác nhau. Chintha và cộng sự (cs) (2013) sàng lọc biến đổi của các gen OXPHOS trên 180 mẫu bao gồm mẫu mô và mẫu máu của bệnh nhân ung thư vú, mẫu mô u và mô lành liền kề của bệnh nhân mắc $u$ vú lành tính và $u$ nang, tuy nhiên không phát hiện được biến đổi nào thuộc gen $M T-A T P 8$ [17]. Kết quả này tương tự với nghiên cứu của Tan và cs năm 2002 [18]. Tipirisetti và cs (2013) phát hiện thấy biến đồi T8426C (F21L) xảy ra ở vị trí bảo thủ của phân tử protein và được dự đoán là đột biến có hại bằng chương trình PolyPhen-2 [19]. Nghiên cứu gần đây của Grzybowska-Szatkowska và cs (2014) đã phát hiện thấy 05 biến đổi của gen $M T-A T P 8$ trong 10/50 cặp mẫu mô u và mô liền kề của bệnh nhân ung thư vú, bao gồm: 1 biến đổi đa hình G8557A và 4 đột biến C8429A, A8439C, T8448C và G8519A. Đa số các biến đổi đều ở dạng đồng tế bào chất (trừ C8429A) và gây ra sự thay đổi axít amin của phân tử protein. Trong số đó, biến đổi A8439C chưa từng được báo cáo trước đây và được cho là có ảnh hưởng đến chức năng của MT-ATP8 [4]. Tương tự, Ghaffarpour và cs (2014) phân tích trên 49 cặp mẫu mô u và mô liền kề của bệnh nhân ung thư vú cũng phát hiện thấy 5 biến đổi của gen $M T-A T P 8$ trong 4/49 trường hợp (chiếm $8,16 \%$ ). Trừ 2 biến đổi $\mathrm{T} 8542 \mathrm{C}$ và G8557A, 3 biến đổi làm thay đổi trình tự axít amin $\mathrm{A} 8384 \mathrm{G}$ (T7A), T8567C (S68P) và G8572A (G69S) đều được cho là có tác động đến phân tử protein [20]. Nghiên cứu trên 30 bệnh nhân ung thư vú người Mizoram, Ân Độ và nhóm đối chứng, Thapa và cs (2016) đã tìm thấy 1 đột biến C8414T (L17F) của gen $M T$ $A T P 8$ trong các mẫu nghiên cứu. Đột biến này nằm ở vị trí bảo thủ và làm thay đổi trình tự axít amin từ leucine thành phenylalanine, do đó được dự đoán là có ảnh hưởng đến phân tử $M T$ ATP8. Trong nghiên cứu của chúng tôi, biến đổi của gen $M T-A T P 8$ được sàng lọc bằng giải trình tự trực tiếp trên 35 mẫu mô của bệnh nhân ung thư vú và 26 mẫu máu đối chứng. Tần suất biến đổi thấp của gen $M T-A T P 8$ cũng tương đồng với các kết quả nghiên cứu trước đây. Kết quả đã xác định được 5 biến đổi, trong đó có 2 biến đổi chỉ thấy xuất hiện ở mẫu mô của bệnh nhân (C8410T và $\mathrm{C} 8417 \mathrm{~T}), 1$ biến đổi chỉ xuất hiện ở nhóm đối chứng (A8440G) và 2 biến đổi xuất hiện đồng thời ở cả mẫu mô của bệnh nhân và mầu máu đối chứng (C8414T và T8473C). Trừ biến đổi C8414T, các biến đổi còn lại chưa thấy được công bố trước đây trong các nghiên cứu trên đối tượng bệnh nhân ung thư vú [6]. Đặc biệt, có $2 / 5$ biến đổi $(\mathrm{C} 8414 \mathrm{~T}$ và $\mathrm{C} 8417 \mathrm{~T})$ làm thay đổi trình tự axít amin từ leucine thành phenylalanine ở vị trí bảo thủ của phân tử protein $\mathrm{A} 6 \mathrm{~L}$ và được dự đoán là có tác động đến phân tử protein tương ứng. Trong đó, biến đổi $\mathrm{C} 8417 \mathrm{~T}$ chỉ được phát hiện thấy trong 1/102 mẫu mô của bệnh nhân ung thư vú mà không thấy có trong nhóm đối chứng, do đó biến đổi này có thể có mối liên quan đến bệnh. Trong nghiên cứu trước đây của PeruccaLostanlen và cs (2000), biến đổi đồng tế bào chất $\mathrm{A} 8381 \mathrm{G}(\mathrm{T} 6 \mathrm{~A})$ nằm ở vị trí bảo thủ cao của gen $M T-A T P 8$ cũng được tìm thấy trong mẫu mô của bệnh nhân và không xuất hiện trong nhóm đối chứng. Biến đổi này được cho là có thể ảnh hưởng đến độ ổn định và hoạt động của phức hệ tổng hợp ATP, dẫn đến giảm sản xuất ATP và có thể gây bệnh [21]. Tương 
tự, Mkaouar-Rebai và cs (2010) cũng phát hiện thấy biến đổi A8411G (M16V) ở vị trí bảo thủ của gen $M T-A T P 8$ chỉ xuất hiện ở mẫu bệnh và không xuất hiện trong nhóm đối chứng. Biến đổi này có thể gây ra sự rối loạn chức năng tổng hợp ATP do có tác động đến phân tử MT-ATP8 và do đó có thể liên quan đến bệnh [9].

Bảng 3. Một số biến đổi của gen MT-ATP8 đã được báo cáo trong các loại ung thư

\begin{tabular}{llllll}
\hline TT & Loại ung thư & Vị trí & Biến đổi & $\begin{array}{l}\text { Thay đổi axít } \\
\text { amin }\end{array}$ & Tài liệu \\
\hline 1 & Ung thư buồng & 8392 & $\mathrm{G} \rightarrow \mathrm{A}$ & Không & {$[13]$} \\
& trứng & 8410 & $\mathrm{C} \rightarrow \mathrm{T}$ & Không & {$[12]$} \\
& & 8414 & $\mathrm{C} \rightarrow \mathrm{T}$ & L17F & {$[13]$} \\
& 8459 & $\mathrm{~A} \rightarrow \mathrm{G}$ & $\mathrm{N} 32 \mathrm{D}$ & {$[13]$} \\
& 8472 & $\mathrm{C} \rightarrow \mathrm{T}$ & $\mathrm{P} 36 \mathrm{~L}$ & {$[12]$} \\
& & 8473 & $\mathrm{~T} \rightarrow \mathrm{C}$ & Không & {$[13]$} \\
& Ung thư tuyến & 8468 & $\mathrm{C} \rightarrow \mathrm{T}$ & Không & {$[15]$} \\
& giáp & 8472 & $\mathrm{C} \rightarrow \mathrm{T}$ & P36L & {$[14]$} \\
& Ung thư tuyến & 8395 & $\mathrm{C} \rightarrow \mathrm{T}$ & Không & {$[16]$} \\
& cận giáp & 8515 & $\mathrm{C} \rightarrow \mathrm{T}$ & Không & {$[16]$} \\
& Ung thư vú & 8384 & $\mathrm{~A} \rightarrow \mathrm{G}$ & T7A & {$[20]$} \\
& & 8414 & $\mathrm{C} \rightarrow \mathrm{T}$ & L17F & {$[6]$} \\
& & 8426 & $\mathrm{~T} \rightarrow \mathrm{C}$ & F21L & {$[19]$} \\
& & 8542 & $\mathrm{~T} \rightarrow \mathrm{C}$ & Không & {$[20]$} \\
& & 8557 & $\mathrm{G} \rightarrow \mathrm{A}$ & Không & {$[20]$} \\
& & 8567 & $\mathrm{~T} \rightarrow \mathrm{C}$ & S68P & {$[20]$} \\
& & 8572 & $\mathrm{G} \rightarrow \mathrm{A}$ & G69S & {$[20]$} \\
\hline
\end{tabular}

Trong nghiên cứu này, ngoài biến đổi của gen MT-ATP8, kết quả phân tích PCR-RFLP còn phát hiện thấy 27/102 trường hợp bệnh nhân (chiếm 26,5\%) có mất đoạn 9 bp ở vùng không mã hóa của ADN ty thể. Mất đoạn 9 bp làm mất đi một trình tự lặp CCCCCTCTA ở vùng giữa gen $M T-C O 2$ và $M T-T K$ là một trong những đa hình $\mathrm{ADN}$ ty thể được nghiên cứu nhiều nhất và đã được báo cáo có liên quan đến một số dạng ung thư như ung thư biểu mô tế bào gan, ung thư biểu mô tế bào thận, ung thư buồng trứng [22][24][13]... Jin và cs (2012) phát hiện thấy tần suất mất đoạn $9 \mathrm{bp}$ có sự khác biệt giữa nhóm bệnh nhân ung thư biểu mô tế bào gan và nhóm đối chứng, trong đó mất đoạn 9 bp có khả năng làm tăng nguy cơ mắc ung thư với $\mathrm{OR}=1,48 ; 95 \% \mathrm{CI}: 1,03-2,14 ; \mathrm{p}=$ 0,027 [23]. Tương tự, theo nghiên cứu của Ren và cs (2015), mất đoạn 9 bp có tần suất cao ở nhóm bệnh nhân ung thư biểu mô tế bào gan (304/390 trường hợp) và tần suất thấp hơn ở nhóm đối chứng (86/431 trường hợp). Mất đoạn này cũng được cho là phổ biến đối với các quần thể ở Châu Á và có thể gây ra sự thay đổi nhiệt động học đối với phân tử tARN ${ }^{\mathrm{Lys}}$ và do đó có vai trò quan trọng trong phát sinh bệnh [24]. Trong nghiên cứu của Bai và cs (2014), mất đoạn $9 \mathrm{bp}$ được cho là có mối liên quan với sự phát triển của bệnh ung thư biểu mô tế bào thận khi tiến hành phân tích đa biến $(\mathrm{OR}=1,599$; $95 \%$ CI: 1,365-1,872; $\mathrm{p}<0,001)$. Do đó, mất đoạn này có thể được sử dụng như một chỉ thị tiên lượng độc lập đối với bệnh nhân ung thư biểu mô tế bào thận. Bên cạnh đó, khi phân tích mối liên quan với các đặc điểm bệnh học của bệnh, kết quả cho thấy có mối liên quan giữa độ tuổi, kích thước khối u và đặc điểm mô học với thời gian sống sót của bệnh nhân. Cụ thể, những bệnh nhân có mất đoạn 9 bp có thời gian sống sót thấp hơn so với những người không có mất đoạn này $(\mathrm{p}<0,001)$. Lý giải cho điều này, nhóm tác giả cho rằng mất đoạn $9 \mathrm{bp}$ có khả năng làm thay đổi biểu hiện gen ở vùng xuôi dòng hoặc ngược dòng, trong đó có một số gen 
đóng vai trò quan trọng trong chuỗi hô hấp của ty thể như MT-ATP8, MT-ATP6, MT-CO3 (cytochrome oxidase III) và $M T-C Y B$ (cytochrome $b$ ). Biểu hiện bất thường của các gen này có thể làm thay đổi chức năng phosphoryl hóa oxy hóa và mức độ stress oxi hóa của tế bào [22]. Trên đối tượng bệnh nhân ung thư vú, theo hiểu biết của chúng tôi, chưa có nghiên cứu nào tập trung phân tích mất đoạn 9 bp ở vùng không mã hóa giữa gen $M T-C O 2$ và $M T-T K$. Do đó, nghiên cứu này sẽ cung cấp dữ liệu ban đầu về tần suất của biến đồi này trên nhóm bệnh nhân ung thư vú người Việt Nam. Theo đó, mất đoạn 9 bp được phát hiện thấy trong $26,5 \%$ bệnh nhân mắc ung thư vú (27/102 trường hợp) và $27 \%$ của nhóm đối chứng (7/26 trường hợp). Tuy nhiên không có sự khác biệt có ý nghĩa thống kê giữa tần suất của mất đoạn này trong nhóm bệnh nhân so với đối chứng. Mặc dù vậy, phân tích theo các đặc điểm bệnh học cho thây mất đoạn 9 bp cao hơn có ý nghĩa thống kê ở độ tuổi $\geq 50 \quad(21 / 62$ trường hợp, chiếm $33,9 \%$ ) so với độ tuổi $<50$ (6/32 trường hợp, chiếm $18,8 \%)$. Điều này có thể được giải thích là các mất đoạn có thể được tích lũy theo thời gian và ở các mô sau nguyên phân với tỉ lệ khác nhau [25]. Do đó, mất đoạn 9 bp được cho là không có mối liên quan với nhóm bệnh nhân ung thư vú người Việt Nam.

\section{Kết luận}

Như vậy, bằng phương pháp PCR - giải trình tự trực tiếp kết hợp với PCR-RFLP đã xác định được 5 biến đổi của gen $M T-A T P 8$ trên 35 mẫu mô u của bệnh nhân ung thư vú và 26 mẫu máu của người bình thường. Trong đó, đột biến C8417T ở vi trí bảo thủ của gen $M T-A T P 8$ là biến đổi hiếm gặp (tần suất $0,98 \%, 1 / 102$ mẫu) và lần đầu tiên được xác định thấy trong một nhóm bệnh nhân ung thư vú người Việt Nam. Bên cạnh đó, mất đoạn 9 bp trong vùng không mã hóa của $\mathrm{ADN}$ ty thể có tần suất $26,5 \%$ ở mẫu mô và $27 \%$ ở mẫu máu được cho là không có mối liên quan với nhóm bệnh nhân này.

\section{Lời cảm ơn}

Nghiên cứu này được tài trợ bởi Đại học Quốc gia Hà Nội trong đề tài mã số QG.16.14.

\section{Tài liệu tham khảo}

[1] Petros JA, Baumann AK, Ruiz-Pesini E, Amin MB, Sun CQ, Hall J, Lim S, Issa MM, Flanders WD, Hosseini SH, Marshall FF, Wallace DC, mtDNA mutations increase tumorigenicity in prostate cancer, Proc Natl Acad Sci U S A (2005), 102(3):719-24.

[2] Wang $X$, The expanding role of mitochondria in apoptosis, Genes Dev (2001), 15(22):2922-33.

[3] Jonckheere AI, Smeitink JA, Rodenburg RJ, Mitochondrial ATP synthase: architecture, function and pathology, $\mathrm{J}$ Inherit Metab Dis (2012), 35(2):211-25.

[4] Grzybowska-Szatkowska L, Slaska B, Rzymowska J, Brzozowska A, Florianczyk B, Novel mitochondrial mutations in the ATP6 and ATP8 genes in patients with breast cancer, Mol Med Rep (2014), 10(4):1772-8.

[5] Adzhubei IA, Schmidt S, Peshkin L, Ramensky VE, Gerasimova A, Bork P, Kondrashov AS, Sunyaev SR, A method and server for predicting damaging missense mutations, Nat Methods (2010), 7(4):248-9.

[6] Thapa S, Lalrohlui F, Ghatak S, Zohmingthanga J, Lallawmzuali D, Pautu JL, Senthil Kumar N, Mitochondrial complex $\mathrm{I}$ and $\mathrm{V}$ gene polymorphisms associated with breast cancer in mizo-mongloid population, Breast Cancer (2016), 23(4):607-16.

[7] Warburg O, On the origin of cancer cells, Science (1956), 123:309-14.

[8] Dumas JF, Rousse D, Servais S, Mitochondria and cancer, Cellular Bioenergetics in Health and Diseases: New Perspectives in Mitochondrial Biology (2012), 115-47.

[9] Mkaouar-Rebai E, Kammoun F, Chamkha I, Kammoun N, Hsairi I, Triki C, Fakhfakh F, A de novo mutation in the adenosine triphosphatase (ATPase) 8 gene in a patient with mitochondrial disorder, J Child Neurol (2010), 25(6):770-5.

[10] Jonckheere AI, Hogeveen M, Nijtmans LG et al., A novel mitochondrial ATP8 gene mutation in a patient with apical hypertrophic cardiomyopathy and neuropathy, J Med Genet (2008), 45:129-33. 
[11] Ware SM, El-Hassan N, Kahler SG et al., Infantile cardiomyopathy caused by a mutation in the overlapping region of mitochondrial ATPase 6 and 8 genes, J Med Genet (2009), 46:308-14.

[12] Liu VW, Shi HH, Cheung AN, Chiu PM, Leung TW, Nagley P, Wong LC, Ngan HY, High incidence of somatic mitochondrial DNA mutations in human ovarian carcinomas, Cancer Res (2001), 61(16):5998-6001.

[13] Zhuo G, Feng G, Leng J, et al., A 9-bp deletion homoplasmy in women with polycystic ovary syndrome revealed by mitochondrial genomemutation screen, Biochem Genet (2010), 48:157163.

[14] Abu-Amero KK, Alzahrani AS, Zou M, Shi Y, Association of mitochondrial DNA transversion mutations with familial medullary thyroid carcinoma/multiple endocrine neoplasia type 2 syndrome, Oncogene (2006), 25:677-84.

[15] Bonora E, Porcelli AM, Gasparre G, et al., Defective oxidative phosphorylation in thyroid oncocytic carcinoma is associated with pathogenic mitochondrial DNA mutations affecting complexes I and III, Cancer Res (2006), 66:608796.

[16] Costa-Guda J, Tokura T, Roth SI, Arnold A, Mitochondrial DNA mutations in oxyphilic and chief cell parathyroid adenomas, BMC Endocr Disord (2007); 7:8.

[17] Chintha R, Kaipa PR, Sekhar N, Hasan Q, Mitochondria and tumors: A new perspective, Indian J Cancer (2013), 50(3).

[18] Tan DJ, Bai RK, Wong LJ, Comprehensive scanning of somatic mitochondrial DNA mutations in breast cancer, Cancer Res (2002), 62(4):972-6.

[19] Tipirisetti NR, Lakshmi RK, Govatati S, Govatati S, Vuree S, Singh L, Raghunadha Rao D,
Bhanoori M, Vishnupriya S, Mitochondrial genome variations in advanced stage breast cancer: a case-control study, Mitochondrion (2013), 13(4):372-8.

[20] Ghaffarpour M, Mahdian R, Fereidooni F, Kamalidehghan B, Moazami N, Houshmand M, The mitochondrial ATPase6 gene is more susceptible to mutation than the ATPase 8 gene in breast cancer patients, Cancer Cell Int (2014), 14(1):21.

[21] Perucca-Lostanlen D, Narbonne H, Hernandez JB, et al., Mitochondrial DNA variations in patients with maternally inherited diabetes and deafness syndrome, Biochem Biophys Res Commun (2000), 277(3):771-5.

[22] Bai Y, Guo Z, Xu J, Zhang J, Cui L, Zhang H, Zhang S, The 9-bp deletion at position 8272 in region $\mathrm{V}$ of mitochondrial DNA is associated with renal cell carcinoma outcome, Mitochondrial DNA A DNA Mapp Seq Anal (2014), 27(3):19735.

[23] Jin Y, Yu Q, Zhou D, Chen L, Huang X, Xu G, Huang J, Gao X, Gao Y, Shen L, The mitochondrial DNA 9-bp deletion polymorphism is a risk factor for hepatocellular carcinoma in the Chinese population, Genet Test Mol Biomarkers (2012), 16(5):330-4.

[24] Ren W, Li Y, Li R, Feng H, Wu S, Mao Y, Huang L, Mitochondrial intergenic COII/tRNA(Lys) 9bp deletion, a biomarker for hepatocellular carcinoma? Mitochondrial DNA A DNA Mapp Seq Anal (2015), 27(4):2520-2.

[25] Cortopassi GA, Shibata D, Soong NW, Arnheim $\mathrm{N}$, A pattern of accumulation of a somatic deletion of mitochondrial DNA in aging human tissues, Proc Natl Acad Sci U S A (1992), 89(16):7370-4. 


\title{
Alterations of the MT-ATP8 Gene and 9-bp Deletion in Vietnamese Patients with Breast Cancer
}

\author{
Nguyen Thi Tu Linh, Nguyen Thi Thao, Do Thi Dung, Trinh Hong Thai \\ VNU University of Science, 334 Nguyen Trai, Thanh Xuan, Hanoi, Vietnam
}

\begin{abstract}
The MT-ATP8 gene encodes for A6L protein subunit belonging to the proton channel of the ATP synthase. MT-ATP 8 gene's mutations can affect the structure and function of the ATP synthase, which may cause diseases. In this study, alterations of MT-ATP8 gene were investigated in tumor tissues of patients with breast cancer and control blood samples using PCR combined with direct sequencing and PCR-RFLP methods, data were analyzed using bioinformatics tools and statistical methods. Sequencing results revealed 5 variants of MT-ATP8 gene on 35 breast tumor tissues and 26 blood samples of controls, of which two mutations C8414T and C8417T altered the amino acid sequence of the resulting protein. The C8417T was further screened by PCR-RFLP and was found in $0,98 \%(1 / 102)$ of breast tumor samples. This change lead to substitution of lecine to phenylalanine (L18F) in a highly conserved position of $\mathrm{A} 6 \mathrm{~L}$ and was predicted as probably damaging to the structure and function of the protein. Additionally, a $9 \mathrm{bp}$ deletion was also observed in a noncoding region of mtDNA in 26,5\% (27/102) of breast cancer patients and $27 \%(7 / 26)$ of controls. Thus, these results showed that C8417T variant in the conserved position of MT-ATP8 gene was rare and first identified in a group of breast cancer patients in Vietnam.
\end{abstract}

Keywords: Breast cancer, mitochondrial DNA, MT-ATP8. 